\title{
8 Energy Resources and Use: The Present Situation, Possible Sustainable Paths to the Future, and the Thermodynamic Perspective
}

\author{
Noam Lior
}

\subsection{Energy Resources and Use Summary (Year 2008)}

The status of energy resources and use in 2008 is briefly summarized in this section, with some elaboration to follow.

\subsubsection{Current Energy Resources and Consumption}

The current energy-resources and consumption situation has generally worsened relative to that at the end of 2006:

- A major concern (or opportunity?): The price of oil was growing very rapidly, from $\$ 28$ in 2003 to $\$ 38$ /barrel in 2005 and occasionally to above $\$ 80$ in 2006 and peaking at $\$ 147$ in 2008 , but then precipitously dropping to $\$ 40$ by the end of 2008.

- The peak price is 1-2 orders of magnitude higher than the cost of extraction, possibly meaning that financial speculation is overwhelming supply and demand and all technical improvements.

- In 2007, world primary energy-resources use rose by $2.4 \%$, with the increase rate slightly dropping (Fig. 8.1), but is likely to rise again soon, as the large developing countries in Asia keep improving their standard of living; China's rose by $7.7 \%$ (lowest since 2002 ), India's by $6.8 \%$, and the United States' by $1.6 \%$, Japan's dropped by $0.9 \%$, and EU's dropped by $2.2 \%$ (EU is the European Union).

- The reserves-to-production $(\mathrm{R} / \mathrm{P})$ ratio remains rather constant: $\sim 40$ for oil, $\sim 60$ for gas, and 200+ for coal, and mostly rising (Figs. 8.2 and 8.3)! There are probably sufficient oil and gas for this century and coal for two or more.

- Tar sands and oil shales are becoming more attractive and available in quantities probably exceeding those of oil and gas.

- Nuclear power produces $\sim 16 \%$ of world electricity; the number of reactors is increasing very slightly; public perception is improving, new government initiatives started, but the same problems remain.

- Renewable energy resources can satisfy $\sim 2$ orders of magnitude more than the world energy demand, but negative impacts are not inconsequential. Wind 


\section{World consumption}

Million tonnes oil equivalent

Coal: (top-most band)

Hydroelectricity: (second band from top)

Nuclear energy: (third band from top)

Natural gas: (fourth band from top)

Oil: (Bottom band) but oil consumption grew slowly. Oil is still the world's leading fuel, but has lost global market share for six consecutive years, while coal has gained market share for six years.

Figure 8.1. World primary energy consumption 1981-2007 [1].

\section{Reserves-to-production $(\mathrm{R} / \mathrm{P})$ ratios}

\section{Years}

World

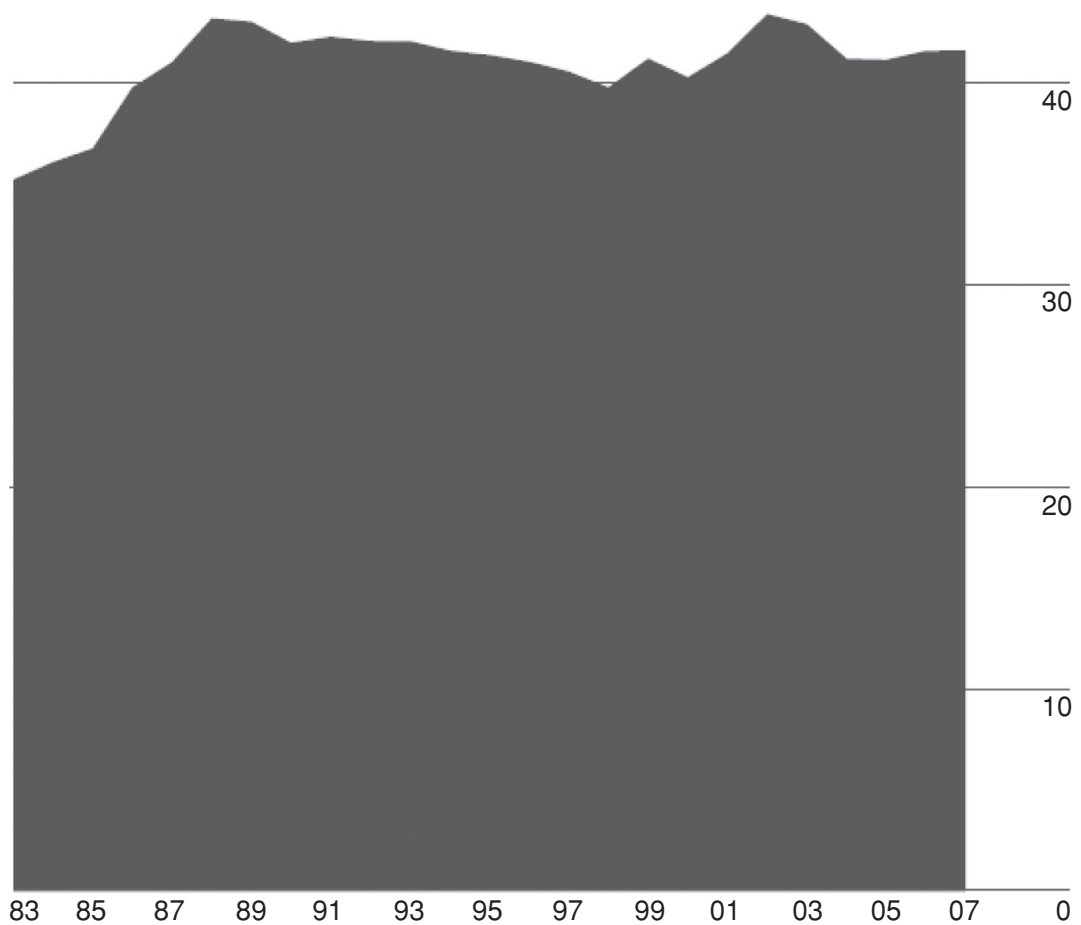

Figure 8.2. The oil R/P ratio, 1982-2007 [1]. 


\section{Fossil fuel reserves-to-production (R/P) ratios at end 2007}

Years

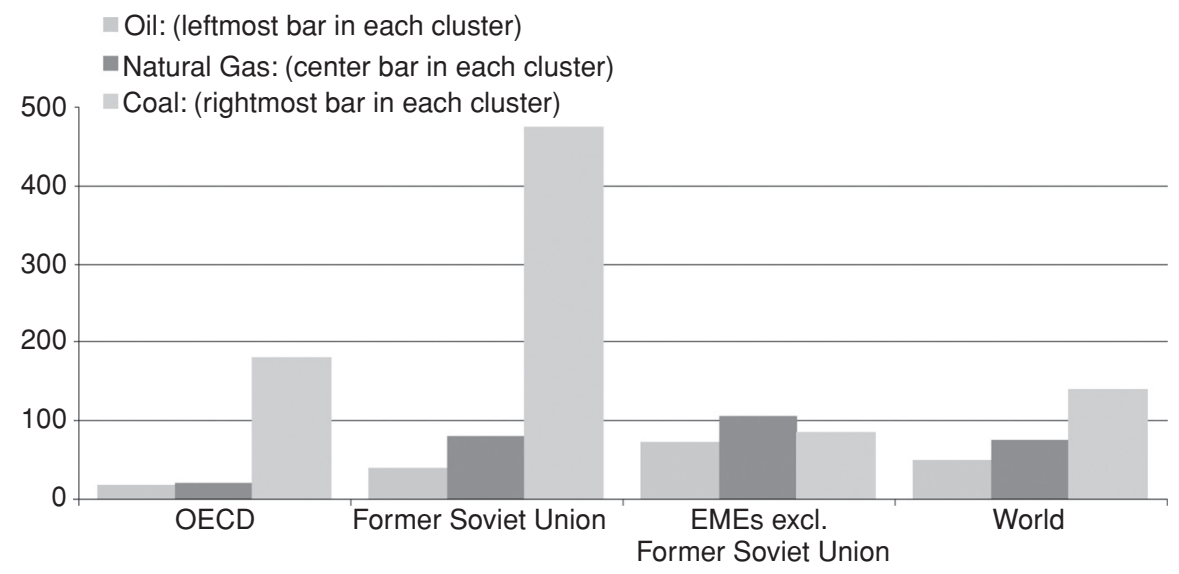

Figure 8.3. The fossil fuels R/P ratio, 2007 [1].

and solar photovoltaics (PVs) are experiencing an exponential growth as costs decrease; interest is renewed in solar-thermal power.

- Strong subsidies for converting food to fuel are increasingly proving to be a mistake, helping to triple the price of foods and reduce their availability, and raise water consumption, all as predicted by some experts before the subsidy program was started.

- Although hydrogen and fuel cells continue to be valuable in the energy portfolio, they have not met the expectations expressed by the huge research-anddevelopment (R\&D) investments made by many governments. This could have been foreseen by more careful early analysis, and some of the moneys and valuable scientists' time could have been spent better.

- The plug-in electric or hybrid car seems to be the preferred route to private transportation. The development of traffic management, roads, and public transit is at least as important.

- Costing of energy resources remains inequitable, as it does not include subsidies, environmental, and other consequences.

- The development of renewable energy resources, and of all energy systems for that matter, is dominated by the highly controlled, cost-unrelated, highly fluctuating, and unpredictable conventional energy-resources prices.

- Fuel and energy consumption in general must be significantly constrained, with due attention to the prevention of the rebound effects.

- The "Living Planet Index" is estimated to have declined since 1970 by about $30 \%$ and the "Ecological Footprint" increased by $70 \%$ in the same period: We seem to be running out of environment much faster than out of resources.

- It is highly inadvisable, and unlikely, that energy resourcing, conversion, and consumption will continue to be developed unsustainably.

- Sustainability is only emerging as a science and must be developed and applied urgently. 


\subsubsection{Future Power Generation}

- The most imminent challenge is that the expected demand for electricity would require during the coming two decades the installation of as much powergeneration capacity as was installed during the entire 20th century.

- Although the plug-in hybrid electric car and electric-driven public transportation seem to be the most promising ways toward energy-efficient transport, this would further raise the demand for electricity in a most significant way, perhaps doubling it.

- To mitigate associated negative effects of such a massive increase, it would increasingly have to be done sustainably.

- Because of its abundance in the most energy-consuming countries such as China, the United States, parts of Europe, India, and Australia, coal is likely to be increasingly the main basic fuel for these plants, partially after conversion to gaseous or even liquid fuels, with the reduced-emissions IGCC (integrated gasification combined-cycle) plant receiving major attention.

- The combined-cycle power-generation plants are the most desirable, having efficiencies of up to about $60 \%$ even at present, less emission than other plants when using natural gas, and a reasonable cost that would keep decreasing as the technology advances further.

- Despite the unresolved problems of waste storage, proliferation risk, and, to some extent, safety, nuclear power plants are likely to be constructed at least for special needs, such as in countries that have much better access to uranium than to fossil fuels and if carbon emissions become costly. The amount of uranium235 in the world is insufficient for massive long-term deployment of nuclear power generation, which can change only if breeder reactors are used, but that technology is not safe and mature enough and is not likely to be in the next couple of decades.

- Wind power generation will be deployed rapidly and massively, but will be limited to regions where wind is economically available and will be limited by the extent and quality of the electricity distribution grid.

- PV power generation will continue increasing in efficiency, decreasing in price, and being employed in many niche applications, but being three to five times more expensive now than other power-generation methods, and also limited by the extent and quality of the electricity distribution grid, and even by availability of materials, it may not reach parity in the coming decade.

- Improvements and technological advances in the distribution and storage of electric power will continue and should be advanced much faster.

- The investments in energy R\&D appear to be much too low, less than half a percent of the monetary value of the energy-resources use, to meet future needs.

\subsection{Introduction}

This chapter is a brief summary of the state of current energy resources and use, their limitations and consequences, and possible paths to the future, including energy research funding trends, especially in the United States. The data are taken from many sources, including the latest (June 2008) energy statistics annual report of 
British Petroleum (BP) for 2007 [1], ${ }^{1}$ the excellent websites of the U.S. Department of Energy (USDOE) [2], its Energy Information Administration [3], Office of Budget [4], Office of Energy Conservation and Renewable Energy [5], Office of Fossil Energy [6], and the National Renewable Energy Laboratory [7], the Energy Research website of the EU [8], the International Energy Agency (IEA) [9], and the International Atomic Energy Agency [10]. The analysis, interpretation, and comments are entirely the author's and do not represent any institutional or government views. Reviews of a similar nature were published by the author for the situation in 2002 and 2008 [11, 12] and in 2009 [13] to update this very dynamic field; this chapter uses the latter data.

A decline in energy research experienced during the 1980s was somewhat arrested toward the end of the 1990s, primarily because of increasing concerns about global warming from energy-related combustion. This has invigorated R\&D in efficiency improvement, use of energy sources that do not produce $\mathrm{CO}_{2}$, and in methods for $\mathrm{CO}_{2}$ separation and sequestration. The interest in energy has received another important boost in the last couple of years, driven by the exponentially rising energy consumption by the highly populated countries of China and India, accompanied by the heightening tensions with many of the oil- and gas-producing countries. Interest in the energy issue and support for energy $R \& D$ are now rising rapidly, abetted by concerns about energy-resources security. The EU and Japan appear at present to have and to be able to afford the most forward-looking and extensive programs, partially because they do not have to bear the enormous relatively recent defense expenses that the United States does.

\subsection{Sustainable Energy Development}

\subsubsection{The Motivation for Sustainable Development}

Energy development is increasingly dominated by major global concerns of overpopulation, pollution, deforestation, biodiversity loss, and global climate deterioration. For example, more than $20 \%$ of the Arctic ice cap melted away between 1979 and 2003 [14], the Living Planet Index, a metric that measures trends in the Earth's biological diversity, is estimated to have declined since 1970 by about $30 \%$, and the Ecological Footprint (defined in [15], extended in [16]), which is the area of biologically productive land and water needed to provide ecological resources and services including land on which to build and land to absorb $\mathrm{CO}_{2}$ released by burning fossil fuels, increased by $70 \%$ in the same period [17]. ${ }^{2}$ These trends are clearly unsustainable and alarming.

Obviously, energy-resources consumption increases with population size, but not in a linear way: A new population from developing countries typically requires more energy resources per capita than their parents did. Although the rate of population increase had been dropping since the 2.2\%/year peak in 1962 to $1.2 \%$ /year

1 Although British Petroleum (BP) has published the Annual Statistical Review of World Energy for 57 years without significant challenges and serves most frequently as the source of the proved fuel reserves data, the accuracy is unknown and is subject to large errors.

2 Although there is an ongoing argument about the proper definition of the Living Planet Index and the Ecological Footprint metrics, the general alarming trends appear to be correct. 


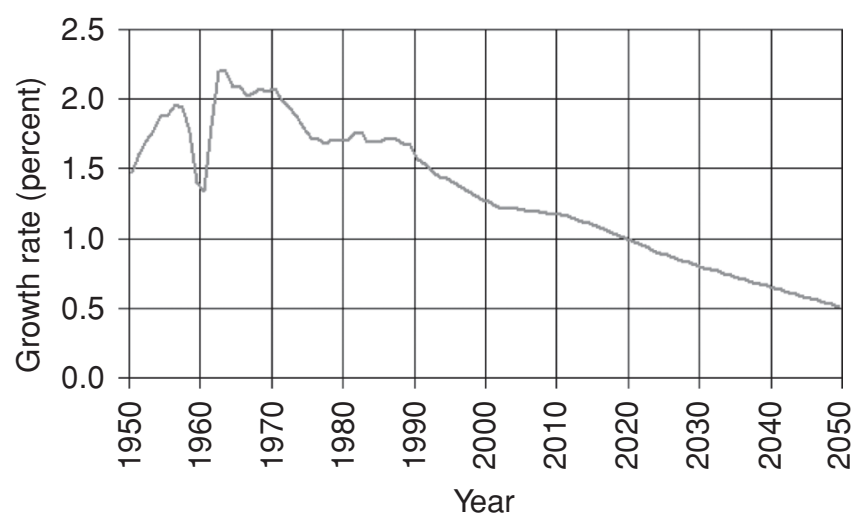

Figure 8.4. World population growth rates 1950-2050 [18].

currently (Fig. 8.4) [18], the increase from the current 6.7 billion to the projected 9.6 billion in 2050 is $43 \%$. The projections are obviously in some doubt, especially if the most populous countries, such as China and India, do not continue or start family size control. It would be impossible to achieve sustainable development if population size is not seriously addressed.

To prevent disastrous global consequences, it would increasingly be impossible to engage in large-scale energy-related activities without ensuring their sustainability, even for developing countries in which there is a perceived priority of energy development and use and power generation over their impact on the environment, society, and indeed on the energy sources themselves. Although having various definitions [19-21], here the original broad one is simply given, that sustainable activities mean that they meet the current needs without destroying the ability of future generations to meet theirs, with a balance among economic, social, and environmental needs.

\subsubsection{Sustainability Analysis}

Clearly the quantification of a project's sustainability metrics (indicators) is the first step in sustainable development, design, and monitoring, but it is very difficult because these are large very complex systems that have technical, ecological, economic, and societal components [19]. It is of vital importance to have, where available, or to develop, where not, agreeable and unambiguous definitions of all the needed metrics. Unfortunately, even the more technical and economic metrics are not always well defined and internationally agreed on yet. For example, it was discussed in some detail in [22] the definitions of and differences among energy, exergy, second law, and economic efficiencies, energy criteria considering environmental effects, and embodied energy payback. Exergy and emergy were proposed by several authors to serve, arguably, as metrics for environmental and even social aspects [23-25]. Entropy generation was proposed as a metric for the sustainability of energy-unrelated materials processing for manufacturing focused on product quality conditions rather than on energy consumption [26].

All the needed metrics must obviously satisfy the laws and other facts of nature. Observation of the laws of nature, such as the second law of thermodynamics, not only avoid wrong metrics, but also provide effective guidance for improvements. 
In that context, it is increasingly recognized and included in practically all textbooks on thermodynamics and energy systems design [27, 28] that exergy ${ }^{3}$ (or second law) analysis must be added to conventional energy accounting analysis during the conception, analysis, development, and design of such systems [29]. Only exergy analysis can identify the specific irreversibilities and is uniquely required for providing the guidance needed in this process. The benefits of exergy analysis are clearly demonstrated in such an analysis of a simple Rankine cycle described in [30]. Energy analysis indicates that the major energy loss, $70 \%$, is due to the heat rejected in the condenser. Examination of the exergy analysis chart shows, however, that this large energy loss amounts to only $3 \%$ of the fuel exergy, and even complete elimination of the condenser heat rejection (if it were at all feasible) would increase the cycle efficiency by up to only three percentage points. Of course, this is because the heat rejected in the condenser is at a low temperature, only slightly elevated above that of the ambient, and thus has commensurately little potential to perform work despite its large energy. Another very significant difference between the energy and exergy analyses is the fact that the exergy analysis identifies the major losses, $69 \%$, to be in the boiler, because of the combustion and gas-to-steam/water heat transfer processes, whereas the energy analysis associates no loss with these processes. Finally, the exergy analysis attributes much less loss to the stack gas than the energy analysis does. The example shows it is only exergy analysis that can correctly identify and evaluate the losses (irreversibilities) that diminish the ability of processes to perform useful work.

An example of how proper thermodynamic analysis and process experience can reduce irreversibility and energy consumption in chemical technology processes is shown in [31]. Thermodynamic reversibility requires that all process driving forces, such as temperature, pressure, and chemical potential differences, be zero at all points and times. Thus the theoretical thermodynamically reversible chemical process must proceed along an equilibrium line that is in chemical equilibrium at each point of a reactor. Accordingly, the driving force for the process must be zero throughout the entire process, not just at the end. Such a theoretical process results in the production of the maximal amount of useful work or in the consumption of the minimal amount of work. Unfortunately, a reversible chemical process operates at an infinitesimally slow rate and requires an infinitely large plant. To operate a chemical process in finite time and at finite cost, it is necessary to have finite driving forces, i.e., to expend some thermodynamic availability (exergy) and, as a result, to consume energy resources. The goal of the process designer is to expend this thermodynamic availability wisely while achieving the technological goals of

3 Exergy ( $a$ ) is defined as the measure of a system's potential to perform useful work between any given state and the so-called "dead state," (subscript 0 in the following equation) at which the system can undergo no further spontaneous processes:

$$
a=h-h_{0}-T_{0}\left(s-s_{0}\right),
$$

where $h$ is the enthalpy and $s$ is the entropy. Because enthalpy is the measure of the energy in flow systems, the preceding equation shows clearly that the portion of the energy $h$ that cannot be converted to useful work is the product $T_{0} s$. Some general references on exergy are M. J. Moran, Availability Analysis (Prentice-Hall, Englewood Cliffs, NJ, 1982); J. Szargut, Exergy Method (WIT Press, Southampton, Boston, 2005); M. J. Moran and H. N. Shapiro, Fundamentals of Engineering Thermodynamics, 6th ed. (Wiley, Hoboken, NJ, 2008). 
the process. Too large a driving force expends more exergy than is necessary and wastes energy resources, whereas too small a driving force requires excessive capital investment. In particular, the designer should avoid an apparatus that has too large a driving force in one part and too small a driving force in another part. In such a case, both energy resources and capital are wasted. The study ends with twelve second law of thermodynamics "commandments" for reducing entropy generation and energy consumption, up from three proposed 47 years earlier in a paper by Denbigh [32].

Consideration of other facts of nature, such as reliable data on resources availability and accessibility, allows sustainable development planning that takes into account use of a resource for both single or multiple demands and interrelations among the uses of different types of resources. Cogent examples are the discussion of "peak oil," availability of water for exploiting tar sands and oil shales and for many other purposes, and the possible competition over lithium use between batteries for electric vehicles and fusion power generation (if either achieves massive use). Very important is the inverse relationship that often exists in processes between the consumption of paid energy and resources. Two fundamental examples were previously discussed: (1) Increasing energy efficiency by a closer approach to the process thermodynamic reversibility requires a decrease of driving forces and the associated, usually inevitable, increase in equipment materials, and (2) increasing use of renewable energy that is typically available only with very low fluxes thus requires large areas of energy collection. A third example is the use of "waste" energy (such as "waste" or rejected heat), which is also of low exergy potential and thus requires large amounts of equipment, such as heat exchangers. An attempt to start the discussion on quantifying the depletion or resources and of the associated complexities is included in [33].

As an example of somewhat less used/known metrics is the concept of energy embodied $^{4}$ in the production of a plant, in the materials produced by it, and in the materials and labor needed for its operation and for the distribution of its material products to the customer. Increasingly used in ecoconscious design of buildings, it is, however, a very important metric in sustainable development in general. Such a criterion answers, for example, the commonly posed question on the length of time that it takes for an energy-conversion system to generate the energy originally required for its manufacturing and operation. Significantly, it also provides valuable guidance about the importance of the manufacturing, ultimate disposal, and recycling aspects of a product. Furthermore, careful consideration of embodied

4 Some references about embodied energy are D. B. Reister, "The energy embodied in goods," Energy 3, 499-305 (1978); K. Nishimura, H. Hondo, and Y. Uchiyama, "Derivation of energyembodiment functions to estimate the embodied energy from the material content," Energy 21, 1247-1256 (1996); C. Atkinson, S. Hobbs, J. West, and S. Edwards, "Life cycle embodied energy and carbon dioxide emissions in buildings," Ind. Environ. 2, 29-31 (1996); W. R awson, Embodied Energy of Building Materials, Environment Design Guide (Royal Australian Institute of Architects, Manuka, Australia, 1996); B. V. V. Reddy and K. S. Jagadish, "Embodied energy of common and alternative building materials and technologies," Energy Buildings 35, 129-37 (2003); Manufacturing Energy Consumption Survey (USDOE Energy Information Administration), available at http://www.eia.doe.gov/emeu/mecs/contents.html (accessed Oct. 31, 2009); and X. Yan, "Energy demand and greenhouse gas emissions during the production of a passenger car in China," Energy Convers. Manage. 50, 2964-2966 (2009). 
energy is of vital importance in renewable energy development, because renewable energy sources typically use, as previously discussed, significantly larger amounts of material per unit useful energy output than conventional fossil and nuclear fuel plants.

Life-cycle analysis (LCA), the investigation and valuation of the environmental (and often economic and social) impacts of a given product or service caused or necessitated by its existence, is a commonly used tool in sustainability analysis. In its full form, when addressing environmental, economic, and social impacts, it is a cornerstone of sustainable design and development: It systematizes a comprehensive consideration or analysis of all conceivable impacts of a project, process, or product, and its results serve as an objective function, allowing quantitative comparison between alternatives and optimization, based on the chosen sustainability metrics. It is noteworthy, however, that LCA is not equivalent to sustainability analysis but can be a component of it.

The LCA time period may be cradle-to-gate (gate being the exit of the plant that makes the product), cradle-to-grave, cradle-to-cradle (includes recycling), or any period chosen by the LCA performer as long as it is clearly defined. The spatial extent (boundaries) depends on legislation or choice. Because of its increasing use, the LCA procedures were defined by the ISO 14000 environmental management standards.

It must also be recognized from the start that LCAs, just as sustainability analysis in general, are subject to serious uncertainties (cf. [34, 35]), because the future is hard to predict ("The art of prophecy is very difficult, especially with respect to the future"), because the extent of the space of interest and its content or purpose may change with time, and the life-cycle impact may vary with time because of legislation, discovery of new information, changes in attitudes, population, events, etc. These inevitable uncertainties and the difficulties in evaluating them make the value of absolute quantitative LCA outcomes meaningless, but the process and methodology by themselves are very valuable in learning about the object of the LCA and about areas that need better information, and ways that it affects the sustainability pillars of environment, economics, and social impact. It is also useful for considering alternative approaches if all the inputs and scenarios are the same and reasonable. Expectations from LCA outcomes should be constrained by recognition of the uncertainties, and uncertainties can be reduced by less-ambitious LCA goals. Qualitative uncertainty analysis in LCA will improve its value, and the LCA community should develop a better understanding of the importance of uncertainty and variability and develop protocols for reliably characterizing, propagating, and analyzing uncertainty in LCA.

Once all the relevant metrics for a sustainability analysis are determined, they need to be aggregated with sensible weighting factors, the objective function for the system optimization must be determined, and then the an optimal solution must be found. This modeling and solution are also very difficult because the problems are dynamic, multiscale, and in many parts nondeterministic, and the data are difficult to collect, so better knowledge and tools are needed. Achieving sustainability requires a new generation of engineers and scientists who are trained to adopt a holistic view of processes as embedded in larger systems. Useful work to develop sustainability science is under way but much remains to be done. 


\subsection{Future Power Generation}

\subsubsection{The Technologies}

From the 18 billion $\mathrm{kW}$ h of electricity generated worldwide in 2006 , about $66 \%$ is produced from fossil fuel, $17 \%$ from hydropower, $15 \%$ from nuclear fuel, and the remaining $2 \%$ from geothermal, wind, solar, wood, and wastes. Coal provides $62 \%$ of the fossil fuel electric power generation, gas $29 \%$, and oil $9 \%$. Practically all of the coal- and oil-fired electricity generation is by Rankine-type steam power plants, and some of the gas-fired plants use combustion gas turbines. A small but increasing fraction of power generation is by combined-cycle systems, using a topping gas turbine system and bottoming steam turbine one. Such plants have an efficiency approaching $60 \%, 35 \%$ higher than that of regular cycles, at a competitive capital cost. Nuclear power plants generate electricity by means of steam turbine Rankinetype cycles, with an efficiency of about $33 \%$. It is noteworthy that this efficiency is much lower than those of fossil fuel power plants because of the lower top temperature in the nuclear power plants and proportionally increases the amount of waste heat discharge to the environment. Large hydropower plants operate at efficiencies approaching $90 \%$ and large wind power plants below $30 \%$.

\subsubsection{The Future Power-Generation Problem and Likely Solution Trends}

The most eminent problem is that expected demand for electricity would require during the coming two decades the installation of as much power-generation capacity as was installed during the entire 20th century [3]. This translates to the stunning number of one 1000-MW power station brought on line every 3.5 days over the next 20 years, on average!

To mitigate associated negative effects of such a massive increase, it would increasingly have to be done sustainably. The first step is clearly energy conservation, a less wasteful, wiser, and more modest use of electricity.

Because of its abundance in the most energy-consuming countries such as China, the United States, parts of Europe and India, and Australia, coal is likely to be increasingly the main basic fuel for these plants, partially after conversion to gaseous or even liquid fuels. Compared with other energy sources, coal-fueled power plants also produce the cheapest electricity. The extensive use of coal will increase the need for more stringent mining and emissions controls and other ecological and social problems associated with a coal economy. The reduced-emissions IGCC plants, increasingly with $\mathrm{CO}_{2}$ separation, are thus likely to be receiving major attention. Using fossil fuels, the combined cycle plants are the most desirable, having efficiencies of up to about $60 \%$ even at present, less emission than other plants when using natural gas, and a reasonable cost that would keep decreasing as the technology advances further.

Despite the unresolved problems of waste storage, proliferation risk, and, to some extent, safety, nuclear power plants are likely to be constructed at least for special needs, such as countries that have much better access to uranium than to fossil fuels. Furthermore, if carbon emissions are made expensive enough, nuclear power plants would become more viable. At the same time, the amount of 
uranium-235 in the world is insufficient for satisfying the world energy demand by nuclear energy, a situation that can change only if breeder or natural uranium or thorium reactors are used. The technology for breeders is not, however, safe and mature enough, and is not likely to be in the next couple of decades. The use of breeders and natural uranium reactors also produces plutonium, with the associated safety and proliferation problems. The latter problem, as well as that of nuclear waste storage, cans be alleviated if transmutation technology is developed to break down the long-half-life actinides to shorter-half-life elements. Thorium-based reactors are under development, but many problems have to be overcome before commercial units could be built.

The economic competiveness of all renewable energy power-generation plants depends of course on the cost of the fuel used by fossil or nuclear power plants. Wildly fluctuating and unpredictable oil and gas prices make reliable planning of renewable, or even nuclear, power generation nearly impossible.

Wind power generation is typically competitive when oil prices are around $\$ 60 /$ barrel, currently has a respectable worldwide capacity of about $94,000 \mathrm{MWe}$ ( $\sim 2.5 \%$ of the world electric-generation capacity of about 4 million MWe), and will be deployed rapidly and massively, but it will be limited to regions where wind is economically available and limited by the extent and quality of the electricity distribution grid. PV power generation is estimated to be marginally competitive at an oil price above $\$ 150 /$ barrel and will continue increasing in efficiency and decreasing in price. Its widespread use is also is limited by the extent and quality of the electricity distribution grid, and even by the availability of materials. It may not reach parity in the coming decade. Hybrid solar-thermal power plants that use solar heat at a lower temperature and the fossil fuel for raising the temperature of the working fluid prior to its inlet to a turbine, of the type described in [36-38], are becoming competitive. The time dependency of wind and solar power introduces major problems that could be resolved by use of energy storage (expensive and often unavailable when hydro or compressed air storage are considered) or grid storage.

Hydroelectric power provides most of the $\sim 6 \%$ contribution of renewable energy to the total energy supply and shows steady but slow growth. Perhaps the most remarkable event is the addition of 18.2 GWe with Three-Gorges Dam in China. The hydroresources are becoming more limited, and the construction of such projects poses various environmental, social, and security problems; this dam, for example, created an upstream lake of $600 \mathrm{~km}$, displacing millions of people. It is also of importance to note that hydroelectric projects in warm-climate vegetated regions cause significant release of $\mathrm{CO}_{2}$ and methane.

Biomass energy has the very important benefits of contribution to the security of fuel supply, lower greenhouse-gas emissions, and support for agriculture; there are also some important concerns and obstacles. These include the fact that bioenergy production and policies have mostly not been based on a broad cost-and-benefit analysis at multiple scales and for the entire production chain, which is particularly true for bioenergy's impact on agriculture. For example, although many publications extol the advantages of converting corn or other crops to ethanol, many of these analyses are flawed, at least in that they do not consider the entire system and cycle [39]. Furthermore, there is strong concern about the effects on food production and cost: Over the past couple of years, corn prices in the United States have 
doubled despite record crops because of its rapidly increasing use for ethanol production. Filling the 25 -gal $\left(0.094 \mathrm{~m}^{3}\right)$ tank of an SUV with pure ethanol requires over $450 \mathrm{lb}(204.5 \mathrm{~kg})$ of corn - which contains enough calories to feed one person for a year.

Cellulosic source ethanol may be better but final proof is absent, and conversion demonstrations have only started. There is also a significant interest and effort in producing butanol, which is a much better and more transportable fuel than ethanol, and in biodiesel fuels.

It is noteworthy that the biofuels well-to-wheel greenhouse-gas abatement potential is not as certain and high as may be thought: less than $20 \%$ for corn ethanol, but over $90 \%$ for sugar cane based [39]. Furthermore, some recent results have shown that growing plants release methane [40], which has a greenhouse-gas potential at least 20 -fold that of $\mathrm{CO}_{2}$.

IEA analyses and projections for biomass uptake by 2030 at competitive costs are 15 to $150 \mathrm{EJ} / \mathrm{yr}[9,39]$. The proposed research needed for this major progress in using biomass [41] includes development of (1) "new" biomass, by means of improved land use, waste utilization, and crop management, together with modified processing methods; (2) new methods of cultivating and harvesting aquatic organisms; (3) genomics and transgenic plants (e.g., to engineer plants and microorganisms that would yield novel polymers or to maximize carbon for high-energy content); (4) new processes, such as enzymatic conversion of corn carbohydrates to polylactic acid (PLA) and other polymers, and combinations of photosynthetic processes with special enzymes to create solid structures that would intercept sunlight and fix carbon into energy-rich materials; (5) improved use of traditional biomass (lignin and cellulosics) by more efficient gasification, enzymatic conversion of lignocellulosic biomass to ethanol; and (6) cultivation of hybrid rapidly growing plants (e.g., poplar or willow, switchgrass).

Improvements and technological advances in the distribution and storage of electric power must and will continue. These are needed for accommodating varying demands with electricity generated by nonrenewable conventional fuels, and even more important when renewable intermittent sources such as solar and wind are used. Also, the development of superconductors that would become commercial and affordable must continue, as they have great potential in increasing electric system efficiency and allowing economical longer-distance transmission, say, from energy-rich to energy-needy regions.

\subsubsection{Fuel Cells and Hydrogen}

The very active development of fuel cells, encouraged by the governments of practically all industrialized nations, is ongoing, primarily aimed at using hydrogen fuel in transportation, but also for large stationary power-generation units. It seems that this major effort has peaked by now, because various important technical issues must be resolved before fuel cells attain significant market penetration and the cost must be reduced by an order of magnitude. Conducting vigorous R\&D is reasonable, but has to be balanced against equally important support needed for improved internal and external combustion engines that have in some cases already attained efficiency higher than those of fuel cells at much lower costs. 
Hydrogen derived from coal is stated to be the USDOE's primary goal in the fuels program, with a primary objective of developing modules for co-producing hydrogen from coal at prices competitive with crude oil equivalents when integrated with advanced coal power systems (cf. [42]). The development of hydrogen as an energy carrier is also very active by other industrialized countries. Despite its advantages in producing near-zero harmful emissions in the process of its conversion to power and the declared plans for its development, the general opinion of the scientific community in this field is that widespread use of hydrogen as a fuel in the foreseeable future appears to be doubtful because of the high energy demand and emissions in its production, and issues of safety, storage, and distribution.

\subsubsection{Micropower Systems (cf. [43, 44])}

There is increasing interest in the construction and use of very small, of the order of $1000 \mu \mathrm{m}$, power-generation systems for various applications, ranging from the military to the medical. Such systems include miniaturized thermal power cycles and direct-energy-conversion systems, including fuel cells [45], mostly intended to replace batteries as much longer operation and low weight and volume devices. Because the power produced by such a device is of the order of milliwatts at best, it does not at first glance appear that they will be used to produce a significant fraction of the overall power demand. At the same time one cannot help but note that use in very large numbers can create significant worldwide capacity. For example, the many very low-capacity computers that are increasingly being used in just about any electrical device, including cars and home appliances, constitute by now a computing capacity far exceeding the total capacity of the existing personal, workstation, and mainframe computers, and the total power produced by batteries of various types is of the order of magnitude of the total electric power generation.

Micropower generators pose very interesting research, development, and construction challenges, many related to the very complex flow, transport, and thermodynamic phenomena. The extraordinary benefits of micropower generators in many known and yet unknown applications make the challenges associated with their development very worthwhile.

\subsubsection{Further-Future Paths: Fusion and Power From Space}

\subsubsection{Fusion}

The major appeal of this process for power generation is that its fuel is composed of rather abundant elements, deuterium that is plentifully available in ordinary water (a liter of water would thus have an energy content of $300 \mathrm{~L}$ of gasoline) and tritium that can be produced by combining the fusion neutron with the abundant lithium. The radiation from the process is very low and short lived, but the environmental problems are not negligible. Thus fusion has the potential to be a very abundant and relatively clean source of energy, with minimal global-warming emissions. The biggest problem, not yet solved after more than 50 years of research, is to create a fusion reaction that continuously produces more energy than it consumes. Past predictions of success and commercialization repeatedly had a 25-year target, and those have increased to about 35 years based on the ambitious multinational 
International Thermonuclear Experimental Reactor (ITER) program that is constructing a 500-MW fusion test facility in Cadarache, France [46].

\subsubsection{Electricity from Space? (cf. [47, 48])}

Power can be produced in space for terrestrial use by use of a number of energy sources, including solar, nuclear, and chemical. The generated power can be transmitted back to Earth by a number of ways, including transmission by microwaves or laser beams or on-site manufacturing of easily transportable fuels for electrochemical or combustive energy conversion.

This is a very complex method, but in view of the rising demand for energy, the diminishing fuel and available terrestrial area for power plant siting, and the alarmingly increasing environmental effects of power generation, the use of space for power generation seems to be rather promising and perhaps inevitable in the long term: (1) It allows the highest energy-conversion efficiency, provides the best heat sink, allows maximal source use if solar energy is the source, and relieves the Earth from the penalties of power generation; and (2) it is technologically feasible, and both the costs of launching payloads into space and those of energy transmission are declining because of other uses for space transportation, dominantly communications.

The technology for such systems is in principle available, and the major obstacle is the exorbitantly high cost, which under current conditions requires the reduction of all costs by orders of magnitude; for example, space transportation costs by at least a 100 -fold to less than $\$ 200 / \mathrm{kg}$ into orbit, for competitiveness.

It is noteworthy that any comparative economical analysis must be conducted on an equitable basis: here specifically including all of the costs of power generation including those of the environmental effects, resource depletion, and embodied energy. Other issues also need to be resolved, some of a general nature, such as environmental effects and security and legal aspects, and some system specific, such as safety of nuclear power plants and the realization of higher energy-conversion and transmission efficiencies.

Perhaps most interesting is the change of paradigm that space power presents: Earth becomes less of an isolated, closed system. National and international work on this subject should be invigorated so that humankind will continue having the energy it needs for its happiness and, indeed, survival.

\subsection{Some Recent Energy R\&D Budgets and Trends}

The information presented here must be prefaced with a statement that examination of governmental and institutional aims and budgets is very difficult, in part because of duplication and overlap of programs and frequent changes across them, and all the numbers given here are thus not always precise. Perhaps a very cogent introduction is the fact that the average government annual expenditure for renewable energy research for all nations is less than $\$ 1$ per person [39].

The total USDOE budget ${ }^{5}$ dedicated to energy R\&D was requested to increase in 2009 by about $4 \%$, to about $3.9 \mathrm{~B} \$$, and perhaps more than $1 \mathrm{~B} \$$ in basic energy

5 These numbers very likely changed with the advent of the new U.S. administration in 2009. 
sciences (out of the 4.7 B $\$$ USDOE Office of Science after its 19\% increase, which funds also several other areas that are not directly related to energy), for a total of about $5 \mathrm{~B} \$$.

The U.S. Department of Energy's National Renewable Energy Laboratory (NREL) had its budget increased by $80 \%$ during 2007 , to $\$ 378$ million.

Out of the USDOE energy R\&D part, the programs of energy efficiency and renewable energy, fossil energy, and nuclear energy are about equally budgeted, nuclear having a slight lead. This is a significant change in the apportioning compared with the situation in 2006, when energy efficiency and renewables had about half of the budget, with the other two areas a quarter each.

The most important budget changes are as follows:

- $19 \%$ (\$748 million) increase in the DOE's Science programs (nuclear physics including major facilities, materials, nanoscience, hydrogen, advanced computing).

- $27 \%$ decrease in the Energy Conservation and Renewable Energy program [with gains in biomass $(+37 \%)$, wind, geothermal, and building technologies; drop of $31 \%$ in hydrogen].

- $23 \%$ increase in the Fossil Energy program to $\$ 1.13$ billion, which includes

- $\$ 648$ million for coal carbon capture-and-storage (CCS) research, including $\$ 149$ million for sequestration. (It is noteworthy that despite the U.S. administration's refusal to sign the Kyoto 1997 protocol, its stated goal is to reduce greenhouse-gas intensity by $18 \%$ by 2012 ),

- zero for petroleum and natural gas

- $84 \%$ increase (to $\$ 344$ million) for the Strategic Petroleum Reserve (capacity expansion from 727 million barrels to 1.0 billion barrels beginning in fiscal year 2008 and later to 1.5 billion barrels).

- $\$ 1.65$ billion in investment tax credits will accelerate commercial deployment of technologies central to carbon capture and storage.

- Nuclear energy, $\$ 1.4$ billion, up 37\%, including

- $\$ 302$ million to begin investments in the Global Nuclear Energy Partnership (GNEP), enable an expansion of nuclear power in the United States and around the world, promote nuclear nonproliferation goals, and help resolve nuclear waste disposal issues,

- $\$ 495$ million for permanent geologic storage site for nuclear waste at Yucca Mountain, Nevada, planned for 2017 pending many difficult obstacles,

- 3.5-fold increase (over 2007), \$214 million for ITER (fusion) (this is uncertain as of the time of writing).

- $5 \%$ increase (to $\$ 110.6$ million) for the Energy Information Administration to improve energy data and analysis programs.

These numbers are rough because there are research areas in the basic sciences that apply across energy-source categories, and there are separately very large budgets that are dedicated to high-energy physics and to the maintenance of large experimental facilities in the national laboratories.

Japan's energy $\mathrm{R} \& \mathrm{D}$ program is above $2.5 \mathrm{~B} \$$ (three quarters of which are for fission and fusion). 
Table 8.1. A qualitative assessment of promising research directions and their current U.S. government funding trend (valid for the beginning of 2008)

\begin{tabular}{|c|c|c|c|c|}
\hline Direction & Potential & Foreseen improvement & $\begin{array}{l}\text { Time scale } \\
\text { (years) }\end{array}$ & $\begin{array}{l}2009 \\
\text { government } \\
\text { funding trend }\end{array}$ \\
\hline Conservation & 论败败十 & $50 \%$ of use & ongoing & $\theta:$ \\
\hline Transportation & 论动弥十 & $\begin{array}{l}50 \% \text { of use } ; 120 \mathrm{~g} \\
\mathrm{CO}_{2} / \mathrm{km} \text { by } 2012\end{array}$ & $3-20$ & : \\
\hline Biomass & 论计十 & $30 \%$ U.S. energy & $4-40$ & (-):-(;) \\
\hline Wind & 论败识 & $2.5 \mathrm{c} / \mathrm{kW} \mathrm{h}, 15 \%$ & $1-15$ & ;) \\
\hline Solar PV & 论败访十 & Competitive price & $6+$ & (:):- \\
\hline Solar thermal & 论败 & Competitive price & $5+$ & :) \\
\hline Geothermal (deep) & 论动 & Competitiveness & 20 & 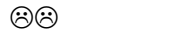 \\
\hline Hydrogen & 弥弥 & Affordable transport fuel & 15 & (:) \\
\hline Fossil fuel power & 证弥 & $\begin{array}{l}65 \%-75 \% \text { efficiency } \\
\sim 0 \text { emissions }\end{array}$ & $6-15$ & (:): \\
\hline Oil and gas & 计 & $\begin{array}{l}\text { Exploration, recovery, } \\
\text { transportation }\end{array}$ & $3-15$ & :(:): \\
\hline Coal & 计十 & $\begin{array}{l}\text { Exploration, recovery, } \\
\text { transportation, conversion }\end{array}$ & 7 & ;) \\
\hline Global warming/CO ${ }^{2}$ & 论败 & $0 \mathrm{CO}^{2}$ & $10-15$ & (-):- \\
\hline Fuel cells & 斻十 & $60 \%+;$ price & 9 & : : \\
\hline Superconductivity & 论败识 & Order of magnitude & $30+$ & :): \\
\hline Nuclear fission & 岤 & $\begin{array}{l}\text { Manageable wastes, no } \\
\text { proliferation }\end{array}$ & 9 & (-):- \\
\hline Nuclear fusion & 论败谈 & Feasibility & $25+$ & (:) \\
\hline Micropower & 论弥访 & Cost, market penetration & $7+$ & (-):- \\
\hline Space power & 论论访＋？ & Competitiveness & $50+$ & $\theta ;$ \\
\hline
\end{tabular}

Note: :-, increased; :, decreased.

The EU (which is the largest importer and second-largest consumer of energy in the world) 7th Framework Programme (2007-2013) had a 50\% increase in the energy area (energy, environment, transport) over the 6th program and is about $1.75 \mathrm{~B} \$$ plus $0.84 \mathrm{~B} \$$ for the nuclear research in Euratom. Some of the goals for the year 2020 include a $20 \%$ reduction of energy use, a $20 \%$ share to renewables, and all new coal power plants being of the CCS type. It is noteworthy that individual European countries also have their own energy R\&D budgets that in total exceed that of the EU.

Table 8.1 summarizes the author's view of the promising energy R\&D areas, their potential, foreseen improvements and their time scale, and last year's trends in government funding.

\subsection{Possible Paths to the Future}

The first step in any path to the future is wiser use of the energy resources, also referred to as conservation. This would include elimination of obvious waste, higher energy-conversion efficiency, substitution for lower-energy-intensity products and processes, recycling, and more energy-modest lifestyles. 
The omnificent politician, publisher, and scientist Benjamin Franklin (who also founded the University of Pennsylvania in 1740), a believer in conservation and frugality, wrote "a penny saved is a penny earned." In the energy area in general, and in power generation in particular, one could safely say that "a Joule saved is worth significantly more than a Joule earned": it takes significantly more than $1 \mathrm{~J}$ of energy to generate $1 \mathrm{~J}$ of power. This is amplified severalfold when one considers the resources and environmental impact associated with the construction and operation of a power plant or even a vehicular engine. It is clear therefore that the first priority in meeting the challenges of the 21 st century is energy conservation, but not implemented in a way that would deprive large fractions of humanity of the basic comforts of life. Indeed, as one of the drafters and signers of the U.S. Constitution, Franklin believed in facilitating people's "pursuit of happiness" and practiced it himself whenever he could. Such pursuit is made very difficult, or impossible, for a population living under energy-conservation measures that it considers to be harsh. Indeed, a lifestyle of health and sustainability study conducted in the United States in 2008 by the Natural Marketing Institute (www.nmisolutions.comlclohas.html) found that there are very few consumers $(5 \%-10 \%)$ who are willing to accept higher cost or lesser performance of a product that has environmental benefits. The majority felt that, although environmental issues are important, they are not willing to make sacrifices [49].

The pursuit of more efficient and less polluting transportation must include not only vehicular improvements (with preference for the plug-in electric or hybrid car) but also traffic management, significant development of efficient public transit, and redesign of cities.

Buildings are the biggest single contributor, $\sim 45 \%$, to world energy and greenhouse-gas emissions. An excellent and practically attainable way to reduce this problem is the design and retrofit of buildings such that they consume less energy (including embodied energy) over their lifetime, with and without incorporation of renewable-energy sources, and further with an extension to "eco-efficient" buildings that not only reduce their negative environmental impact but also help heal and improve the environment. A broader method is to design residential communities in a way that reduces both indirect use of energy and emissions by reducing the need for transportation and resources by the residents.

At least for this century, more efficient and less polluting use of fossil fuels, as well as better and cleaner exploration and extraction of such fuels, is continuing to be pursued. Important steps must also be taken to prevent energy-efficiency "rebound," the frequent outcome in which higher efficiency and lower costs lead to increased consumption (cf. [50, 51]).

It appears that the massive use of nuclear fission power would be stymied unless permanent and economical solutions to nuclear waste, such as element transmutation, can be attained. Nuclear fusion power could produce a very satisfactory long-term solution, but is still rather far from being achieved. R\&D and implementation of renewable energy must continue vigorously, with the most promising technologies being solar PVs, wind, and, to some extent, biomass. Very deep drilling, or generally access, technologies for reaching the enormous renewable geothermal heat resources should be pursued. 
R\&D to develop commercial superconductors would reduce energy losses significantly, but will take some decades at least. Space power generation for terrestrial use must be explored as a long-term solution.

The inequitable costing of energy resources and their conversion must stop, by governments and industry assigning a true value based on all short- and long-term externalities. In-depth scenario studies are necessary for quantitative forecasting of the best ways to spend government research moneys, but qualitatively, and based on the current knowledge and situation, they should develop effective commercial ways for attaining the just-described objectives.

Sustainability is only emerging as a science and must be developed and applied urgently to provide analysis and evaluation tools. It is of immediate importance because energy conversion and use are associated with major environmental, economical, and social impacts, and all large energy projects should therefore be designed and implemented sustainably.

The critical problems that energy development poses and the possible paths to the future create at the same time great opportunities for respected solutions by the engineering and scientific communities that promote new and expanded creativity, higher employment, and higher job satisfaction. It also offers special prospects for small enterprises and nations that are not hampered by the inertia inherent in larger organizations.

A frequent major obstacle is the political system needed to support rapid and effective movement along the new paths and to plan beyond its tenure, which often prefers solutions that are primarily supportive of its own survival: popular support for sensible paths should be sought and people should be educated to diminish this obstacle.

Many of the innovative solutions require very long periods of time. It is of vital importance to start intensively now, so we won't be too late.

\section{REFERENCES}

[1] British Petroleum, Statistical Review of World Energy 2008, available at http://www.bp.com/productlanding.do? categoryId $=6929 \&$ contentId=7044622 (accessed July 31, 2008).

[2] U.S. Department of Energy, http://www.energy.gov/ (accessed July 31, 2008).

[3] U.S. Department of Energy, Energy Information Administration, http:// www.eia.doe.gov/ (accessed July 31, 2008).

[4] U.S. Department of Energy, Office of Management, Budget, and Evaluation (MBE), Office of Budget, http://www.cfo.doe.gov/crorg/cf30.htm (accessed July 31, 2008).

[5] U.S. Department of Energy, Energy Efficiency and Renewable Energy, http://www.eere.energy.gov/ (accessed July 31, 2008).

[6] U.S. Department of Energy, Office of Fossil Energy, http://www.fossil.energy .gov (accessed July 31, 2008).

[7] National Renewable Energy Laboratory, http://www.nrel.gov/ (accessed July 31, 2008).

[8] The European Commission website on Energy Research, http://europa.eu.int/ comm/research/energy/index_en.html (accessed July 31, 2008).

[9] International Energy Agency, http://www.iea.org/ (accessed July 31, 2008).

[10] International Atomic Energy Agency, http://www.iaea.org/ and http://www .iaea.org/programmes/a2/index.html (accessed July 31, 2008). 
[11] N. Lior, "The state and perspectives of research in the energy field," invited keynote paper in Advances in Energy Studies: Reconsidering the Importance of Energy, Proceedings of the Third Biennial Workshop, edited by S. Ulgati (2002), pp. 351-364.

[12] N. Lior, "Energy resources and use: The present situation and possible paths to the future," invited keynote lecture for PRES 06 (Ninth Conference on "Process Integration, Modeling and Optimisation for Energy Saving and Pollution Reduction"), joint with CHISA 2006 (17th International Congress of Chemical and Process Engineering), Praha, Czech Republic, August 2006; in revised form in Energy 33, 842-857 (2008).

[13] N. Lior, "Energy resources and use: The present situation and possible sustainable paths to the future," invited keynote presentation for SET 2008, the Seventh Conference on Sustainable Energy Technologies, Seoul, Korea, Aug. 24-27, 2008. (Also in the proceedings published by Korea Institute of Ecological Architecture and Environment, Seoul, Korea, 2009, Vol. 1, pp. 55-67).

[14] NASA, http://www.nasa.gov/centers/goddard/news/topstory/2003/1023esuice .html (accessed July 31, 2008).

[15] M. Wackernagel and W. Rees, Our Ecological Footprints (New Society Publishers, Gabriola Island, British Columbia, Canada, 1996).

[16] H. Nguyen and R. Yamamoto, "Modification of ecological footprint evaluation method to include non-renewable resource consumption using thermodynamic approach," Resources Conserv. Recycl. 51, 870-884 (2007).

[17] WWF (World Wildlife Federation; World Wide Fund For Nature), The Living Planet, http://www.panda.org/news_facts/publications/living_planet_ report/lp_2006/index.cfm (accessed July 31, 2008).

[18] U.S. Census Bureau, http://www.census.gov/ipc/www/idb/worldpopinfo.html (accessed July 31, 2008).

[19] N. Lior, "About sustainability metrics for energy development," invited keynote presentation at the 6th Biennial International Workshop, "Advances in Energy Studies," Graz, Austria, June 29-July 2, 2008 (Graz University of Technology Publication, Graz, Austria, 2008, pp. 390-401).

[20] S. K. Sikdar, P. Glavič, and R. Jain, editors, Technological Choices for Sustainability (Springer, Berlin, 2004).

[21] C. Böhringer and P. E. P. Jochem, "Measuring the immeasurable - A survey of sustainability indices," Ecol. Econ. 63, 1-8 (2007).

[22] N. Lior and N. Zhang, "Energy, exergy, and second law performance criteria," Energy 32, 281-296 (2007).

[23] H. S. Yi, J. L. Hau, N. U. Ukidwe, and B. R. Bakshi, "Hierarchical thermodynamic metrics for evaluating the environmental sustainability of industrial processes" Environ. Prog. 23, 302-314 (2004).

[24] S. E. Jørgensen and S. N. Nielsen, "Application of exergy as thermodynamic indicator in ecology," Energy 32, 673-685 (2007).

[25] J. Dewulf, H. Van Langenhove, B. Muys, S. Bruers, B. R. Bakshi, G. F. Grubb, D. M. Paulus, and E. Sciubba, "Exergy: Its potential and limitations in environmental science and technology," Environ. Sci. Technol. 42, 2221-2232 (2008).

[26] D. P. Sekulić, "An entropy generation metric for non-energy systems assessments," Energy 34, 587-592 (2009).

[27] A. Bejan, G. Tsatsaronis, and M. Moran, Thermal Design and Optimization (Wiley, New York, 1996).

[28] J. Szargut, Exergy Method: Technical and Ecological Applications (WIT Press, Southampton, UK, 2005).

[29] N. Lior, "Thoughts about future power generation systems and the role of exergy analysis in their development," Energy Conversion Manage. J. 43, 11871198 (2002). 
[30] N. Lior, "The second law of thermodynamics and entropy," in Handbook of Engineering, edited by E. Dorf (CRC Press, Boca Raton, FL, 1996), Chap. 44, pp. 462-478.

[31] I. L. Leites, D.A. Sama, and N. Lior, "The theory and practice of energy saving in the chemical industry: Some methods for reducing thermodynamic irreversibility in chemical technology processes," Energy 28, 55-97 (2003), with Corrigendum, Energy 29, 301-304 (2004).

[32] K. G. Denbigh, "The second-law efficiency of chemical processes," Chem. Eng. Sci. 6, 1-9 (1956).

[33] S. Lems, H. J. Van Der Kooi, and J. de Swaan Arons, "The sustainability of resource utilization," Green Chem. 4, 308-313 (2002).

[34] R. Heijungs and M. A. J. Huijbregts, "A review of approaches to treat uncertainty in LCA," in Complexity and Integrated Resources Management. Transactions of the 2nd Biennial Meeting of the International Environmental Modelling and Software Society, edited by C. Pahl-Wostl, S. Schmidt, A. E. Rizzoli, and A. J. Jakeman Proceedins of the 2nd Blennial Meeting of iEMSs, Complexity and integrated resources management, 14-17 June 2004, Osnabrück, Germany, iEMSs, Orlando, Flo.

[35] S. M. Lloyd and R. Ries, "Characterizing, propagating, and analyzing uncertainty in life-cycle assessment - a survey of quantitative approaches," J. Ind. Ecol. 11, 161-169 (2007).

[36] N. Lior, "Solar energy and the steam rankine cycle for driving and assisting heat pumps in heating and cooling modes," Energy Convers. 16, 111-123 (1977).

[37] K. Koai, N. Lior, and H. Yeh, "Performance analysis of a solar-powered/fuelassisted Rankine cycle with a novel 30hp turbine," Solar Energy 32, 753-764 (1984).

[38] J. Dersch, M. Geyer, U. Herrmann, S. A. Jones, B. Kelly, R. Kistner, W. Ortmanns, R. Pitz-Paal, and H. Price, "Trough integration in power plants - A study on the performance and economy of integrated solar combined cycle systems," Energy 29, 947-959 (2004).

[39] R. K Dixon and R. E. Sims, "IEA secretariat perspectives on bioenergy," presentation at the International Renewable Energy Alliance meeting " $100 \%$ Renewable Energy Mix Scenarios for Africa and Asia," Hon. Peter Rae, Chair, United Nations, New York, May 7, 2007. Data from the International Energy Agency, http://www.iea.org/RDD/ (accessed July 31, 2008).

[40] F. Keppler, J. G. Hamilton, M. Brass, and T. Rockmann, "Methane emissions from terrestrial plants under aerobic conditions," Nature (London) 439, 187191 (2006).

[41] U.S. Department of Energy, "The biobased materials and bioenergy vision," draft, July 18, 2001. Available at http://www1.eere.energy.gov/biomass/pdfs/ final_2006_vision.pdf-1355.5KB (accessed July 31, 2008).

[42] U.S. Department of Energy, Office of Fossil Energy Vision 21 program, http://www.fossil.energy.gov/programs/powersystems/vision21/index.html (accessed July 31, 2008).

[43] A. Majumdar and C. L. Tien, "Micro power devices," Microscale Thermophys. Eng. 2, 67-69 (1998).

[44] A. Kribus, "Thermal integral micro-generation systems for solar and conventional use," ASME J. Solar Energy Eng. 124, 180-197 (2002).

[45] J. Holladay, E. O. Jones, M. Phelps, and J. Hu, "High-efficiency microscale power using a fuel processor and fuel cell," in Components and Applications for Industry Automobiles, Aerospace and Communication, edited by H. Helvajian, S. W. Janson, and F. Laermer, Proc. SPIE 4559, 148-156 (2002).

[46] U.S. Department of Energy, Department of Science, http://www.science .doe.gov/ News_Information/News_Room/2006/ITER/index.htm (accessed July 31, 2008). 
[47] P. E. Glaser, F. P. Davidson, and K. I. Csigi, editors. Solar Power Satellites, the Emerging Energy Option (Ellis Horwood, New York, 1993).

[48] N. Lior, "Power from space," Energy Convers. Manage. J. 42, 1769-1805 (2001).

[49] L. Sauers and S. Mitra, "Sustainability innovation in the consumer products industry," Chem. Eng. Prog. 105, 36-40 (2009).

[50] H. Herring, "Energy efficiency - A critical view," Energy 31, 10-20 (2006).

[51] S. Sorrell and J. Dimitropoulos, "The rebound effect: Microeconomic definitions, limitations and extensions," Ecol. Econ. 65, 636-649 (2008). 